\title{
Computed tomography and magnetic resonance imaging in the osseous phase of Nasu-Hakola disease
}

Tomografia computadorizada e ressonância magnética na fase óssea da doença de Nasu-Hakola

Christiana Brenner ${ }^{1}$, Carlos Eduardo Speck-Martins ${ }^{1}$, Jaime Moritz Brum¹, Leandro Tavares Lucato², Claudia da Costa Leite ${ }^{2,3}$

Nasu-Hakola disease (NHD-polycystic lipomembranous osteodysplasia with sclerosing leukoencephalopathy; PLOSL) is a rare autosomal recessive disorder, caused by mutations in two genes: TREM 2 and DAP 12. NHD is characterized by a combination of diffuse bone cysts and pre-senile dementia. Most of the NHD cases first present in early adulthood with skeletal abnormalities (osseous phase). Neurological symptoms manifest in the fourth decade of life as prefrontal syndrome ${ }^{1,2,3}$. A 32 year-old male patient presented bone fractures, usually after minor traumas and cystic lesions on X-Rays (Figure 1). He denied any personality change or memory disturbances. The neurological examination was normal. The neuropsychological tests displayed only easy distractibility. CT and MRI demonstrate abnormalities in the basal ganglia and white matter (Figure 2) showing that imaging findings precedes neuropsychiatric symptoms.

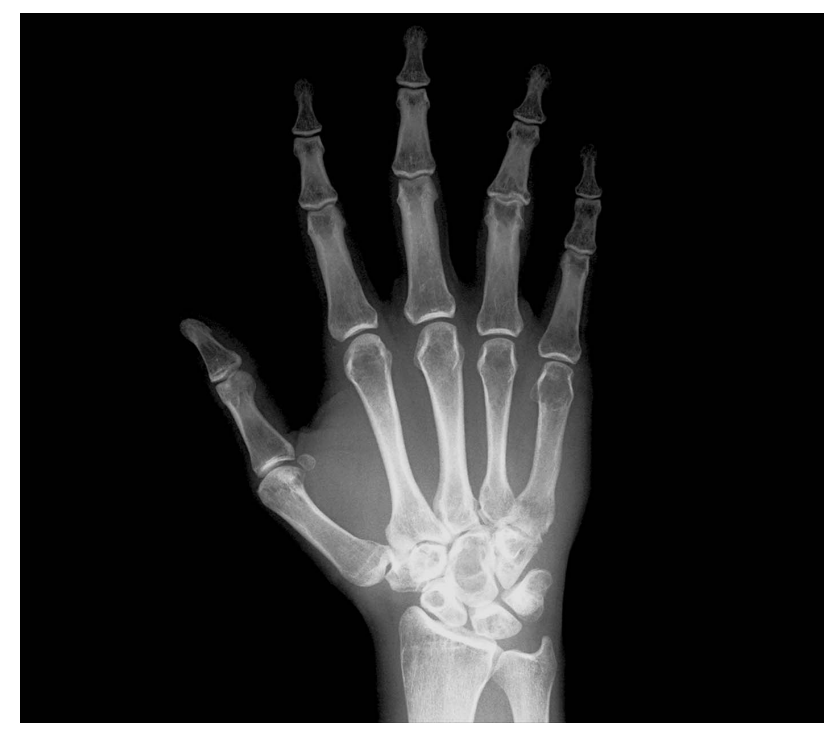

Figure 1. R-xays of the right hand demonstrates multiple cystic lesions in the carpal bones.
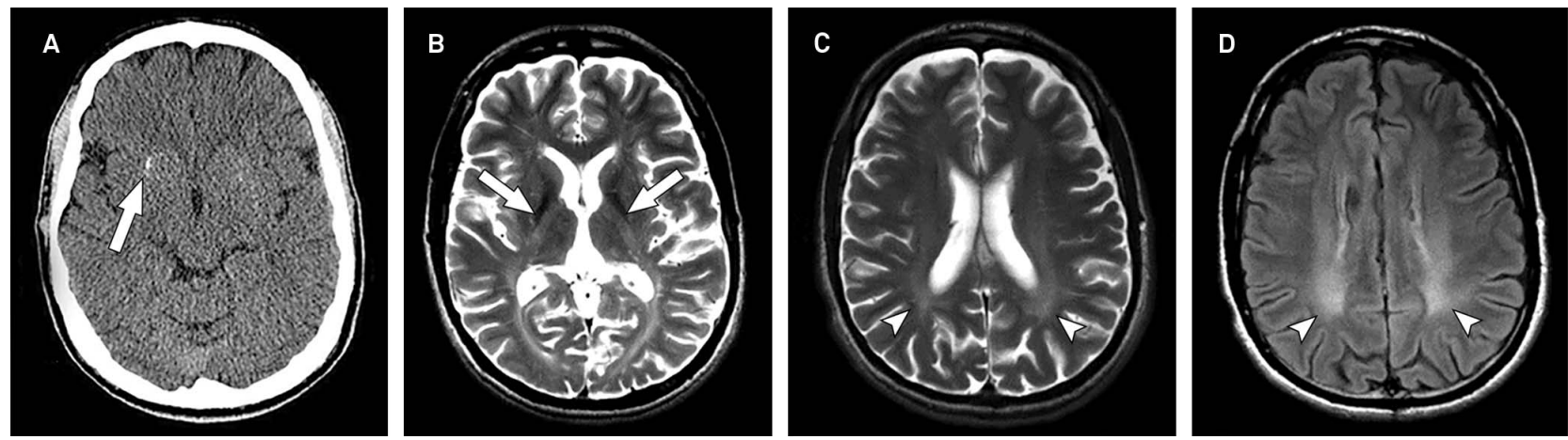

Figure 2. Head CT discloses punctate basal ganglia calcification (arrows in A). Brain MRI, axial T2-weighted (B, C) and axial FLAIR (D) images show diffuse cerebral atrophy, bilateral and symmetric hyperintensity in the posterior limbs of the internal capsules (arrows in B), and in the parieto-occipital periventricular white matter and centrum semiovale (arrowheads in C and D).

${ }^{1}$ Rede Sarah de Hospitais, Brasília DF, Brazil;

${ }^{2}$ Departamento de Radiologia, Faculdade de Medicina, Universidade São Paulo, Sao Paulo SP, Brazil;

${ }^{3}$ University of North Carolina, Chapel Hill, United States.

Correspondence: Claudia Leite; Faculdade de Medicina da USP - Radiologia; Av. Dr. Ovídio Pires Campos, s/n Inrad Portaria 5 Ressonância Magnética; 05403-903 São Paulo SP, Brasil; E-mail: claudia.leite@hc.fm.usp.br

Conflict of interest: There is no conflict of interest to declare.

Received 26 January 2014; Received in final form 22 April 2014; Accepted 12 May 2014 
1. Paloneva J, Autti T, Raininko R, et al. CNS manifestation of NasuHakola disease: A frontal dementia with bone cysts. Neurology 2001;56:1552-1558

2. Klünemann HH, Ridha BH, Magy L, et al. The genetic causes of basal ganglia calcification, dementia, and bone cysts: DAP12 and TREM2. Neurology 2005;64:1502-1507.
3.

Kilic SA, Oner AY, Yuce C, Ozlu IC. Imaging findings of Nasu-Hakola disease: a case report. Clin Imag 2012;36:877-880. 